\title{
Acarboxyprothrombin activity after oral prophylactic vitamin $\mathrm{K}$
}

\author{
R VON KRIES, S KREPPEL, A BECKER, R TANGERMANN, AND U GÖBEL
}

Departments of Paediatrics, Neonatology, Gastroenterology, Haematology, and Oncology, Centre of Child Health, University of Düsseldorf, Federal Republic of Germany

SUMmary The effect of prophylaxis with oral vitamin $\mathrm{K}\left(1 \mathrm{mg}\right.$ vitamin $\mathrm{K}_{1}$ given with the first feed) on the rate of detection of acarboxyprothrombin (PIVKA II) and factor II clotting activity were analysed. Introducing such prophylaxis reduced the rates of detection of PIVKA II activity on day 5 from $48 \%$ to zero. None of the babies given prophylaxis had factor II clotting activity below $40 \%$, compared with 34 of 95 babies not given prophylaxis. This study has important implications in the prophylaxis of both classical and late onset haemorrhagic disease of the newborn.

The need for prophylaxis with vitamin $\mathrm{K}$ has recently been reaffirmed. ${ }^{1}$ There is, however, controversy as to how the vitamin should be given. Several authors have argued that oral instead of parenteral administration would spare babies the discomfort and potential risk of intramuscular or subcutaneous injections. ${ }^{2}{ }^{3}$ Fairly good absorption of vitamin $\mathrm{K}_{1}$ given orally to healthy neonates has recently been reported. ${ }^{3}$ Variation between subjects, however, was considerable, and the safety of oral vitamin $\mathrm{K}$ prophylaxis has therefore been questioned. $^{4}$

In this study we assessed the effect of prophylaxis with oral vitamin $\mathrm{K}$ on the vitamin $\mathrm{K}$ supply of the neonate by analysing acarboxyprothrombin (PIVKA II) activity, a marker for vitamin $\mathrm{K}$ deficiency; we also used a coagulation test for factor II.

\section{Patients and methods}

PIVKA II and clotting analyses were performed in healthy 5 day old full term infants. We first looked at the detection rates of PIVKA II and factor II clotting activity in 95 neonates not given vitamin $\mathrm{K}$ prophylaxis from May to September 1985. We then compared the effect of oral prophylaxis (1 mg vitamin $\mathrm{K}_{1}$ with first feed) on these measurements in a further 95 babies from May to September 1986. The influence of potential seasonal changes could be excluded as both groups were studied during the same months of the year. The Table shows that there were no significant differences in mean birth weights or methods of feeding (breast, formula, or mixed) between the two groups. Blood samples for measurement of PIVKA II activity and factor II clotting analysis were taken from a heel prick on day 5 , at the same time as the compulsory blood sampling for screening tests for inherited disorders of metabolism and hypothyroidism.

PIVKA II activity was determined with crossed immunoelectrophoresis as described previously. ${ }^{5} \mathrm{~A}$ whole blood clotting assay was used for factor II analysis. ${ }^{6}$

All mothers had given informed consent both to the blood sampling and to the vitamin $\mathrm{K}$ regimen.

Table 1 Comparison of two groups of healthy full term infants

\begin{tabular}{|c|c|c|c|c|}
\hline Group & $\begin{array}{l}\text { Mean }(S D) \\
\text { birth weight } \\
(g)\end{array}$ & $\begin{array}{l}\text { No } \\
\text { breast } \\
\text { fed }\end{array}$ & $\begin{array}{l}\text { No breast and } \\
\text { formula fed }\end{array}$ & $\begin{array}{l}\text { No formula } \\
\text { fed only }\end{array}$ \\
\hline A (no prophylaxis) & $3370(399)$ & 66 & 23 & 8 \\
\hline B (1 mg vitamin $\mathrm{K}_{1}$ orally with first feed) & $3380(403)$ & 66 & 21 & 9 \\
\hline
\end{tabular}




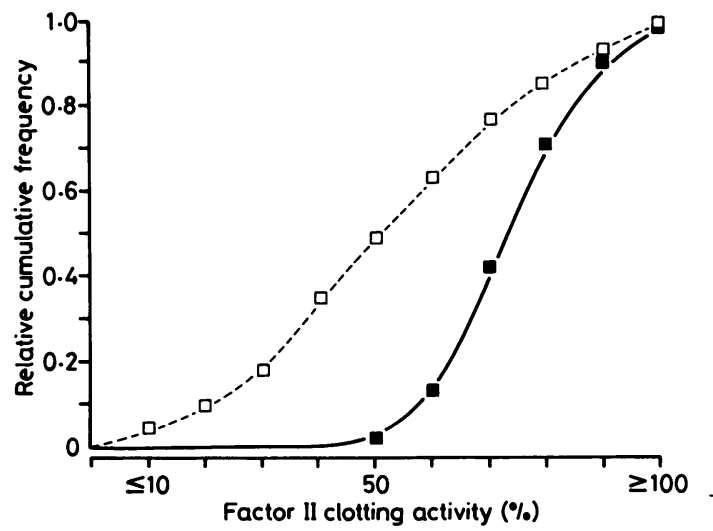

Figure Association between factor II clotting activities in 5 day old healthy neonates and oral prophylaxis with vitamin $K_{1} . \square$ no vitamin $K$ prophylaxis, $1 \mathrm{mg}$ vitamin $K_{l}$ with first feed.

The study was approved by the local ethical committee.

\section{Results}

Of 95 healthy babies not given vitamin K prophylaxis, 47 showed PIVKA II activity; none of the 95 babies given oral vitamin $\mathrm{K}$ did.

The cumulative distribution patterns of factor II clotting activity in babies who had and had not been given prophylactic vitamin $\mathrm{K}$ are shown in the Figure. None of the babies given vitamin $\mathrm{K}$ had factor II clotting activity below $40 \%$, compared with 34 of the 95 babies not given vitamin K. Five of these babies, all exclusively breast fed, had severe hypoprothrombinaemia with factor II clotting activity of less than $10 \%$.

\section{Discussion}

High detection rates of PIVKA II activity in healthy 5 and 6 day old neonates not given vitamin $K$ prophylaxis at birth have been reported. ${ }^{7}$ Apart from confirming these results, our data additionally give clear evidence of severe hypoprothrombinaemia in several of the babies with PIVKA II activity. This prompted us to introduce vitamin $\mathrm{K}$ prophylaxis and to evaluate the effect of an oral regimen.

Oral and intramuscular vitamin $\mathrm{K}$ prophylaxis have been shown to have similar effects on clotting factors dependent on vitamin $K{ }^{8}$ Using a more sensitive marker for vitamin $\mathrm{K}$ deficiency (PIVKA II activity), however, Motohara et al reported a detection rate of PIVKA II activity of $11.4 \%$ in babies given $5 \mathrm{mg}$ vitamin $\mathrm{K}_{2}$ orally at birth. ${ }^{9}$ This prompted us to evaluate the effect of prophylaxis with oral vitamin $\mathrm{K}$ by giving a $1 \mathrm{mg}$ dose of vitamin $\mathrm{K}_{1}$, the only vitamin $\mathrm{K}$ preparation available in Europe. In our study all 95 babies given $1 \mathrm{mg}$ vitamin $K_{1}$ with the first feed had no PIVKA II activity detectable on the fifth day of life and had normal factor II clotting activity. Though the blood sample may have been taken after the nadir of clotting factors dependent on vitamin $\mathrm{K}$, vitamin $\mathrm{K}$ deficiency on previous days would not have escaped detection as PIVKA II has a $50 \%$ disappearance rate of about 50 hours. ${ }^{10}$ These data therefore suggest that oral vitamin $\mathrm{K}_{1}$ given as a $1 \mathrm{mg}$ dose with the first feed protects against vitamin $\mathrm{K}$ deficiency in the neonatal period.

Several explanations might account for the high detection rates of PIVKA II activity in the series reported by Motohara et al. ${ }^{9}$ Firstly, the method might not be specific enough to differentiate between neonatal prothrombin and PIVKA II activity. Secondly, some of the PIVKA II results on day 5 might arise from intrauterine vitamin $\mathrm{K}$ deficiency, as PIVKA II activity was found in $19 \cdot 2 \%$ of the corresponding samples of cord blood with the enzyme linked immunosorbent assay used by Motohara et al. ${ }^{9}$ With our method PIVKA II activity was not detectable in cord blood and interference with PIVKA II activity indicating anamnestic vitamin $\mathrm{K}$ deficiency therefore was unlikely. ${ }^{7}$ Finally, the absorption and metabolism of vitamin $\mathrm{K}_{2}$ might be different from that of vitamin $\mathrm{K}_{1}$.

Even for vitamin $\mathrm{K}_{1}$, however, the absorption in healthy babies varied widely, ${ }^{3}$ but this does not seem to matter for the supply of vitamin $\mathrm{K}$ in the neonatal period. It might, however, be relevant to late onset vitamin $\mathrm{K}$ deficiency, a bleeding disorder that often presents with intracranial haemorrhage in 4-8 week old infants. Three observations (below) related to five cases of bleeding due to late onset vitamin $\mathrm{K}$ deficiency in this hospital cast doubt on the ability of prophylaxis with oral vitamin $\mathrm{K}$ to prevent late onset vitamin $\mathrm{K}$ deficiency.

Massive bleeding after a sample of venous blood had been taken was diagnosed in a 25 day old boy who had received $2 \mathrm{mg}$ vitamin $\mathrm{K}$ orally with the first feed. Partial thromboplastin time and prothrombin time were prolonged, and vitamin $\mathrm{K}$ deficiency was proved when these measurements returned to normal within four hours of subcutaneous injection of $1 \mathrm{mg}$ vitamin $\mathrm{K}_{1}$. This boy had been fed on a formula not supplemented with vitamin $\mathrm{K}$. He showed no clinical symptoms of malabsorption and had not received any antibiotics. At the time the late onset vitamin $\mathrm{K}$ deficiency was diagnosed he had mild cholestasis with slightly abnormal liver function test results, which could not 
be attributed to bile duct atresia, viral hepatitis, cystic fibrosis, or $\alpha$-1-antitrypsin deficiency.

Intracranial haemorrhage due to late onset vitamin $\mathrm{K}$ deficiency was diagnosed in a 45 day old boy who had been given $3 \mathrm{mg}$ vitamin $K_{1}$ orally 24 days before the life threatening bleeding occurred. ${ }^{11}$ The boy, who had not been given vitamin $\mathrm{K}$ prophylaxis at birth, first presented with bleeding from an insect bite when 21 days old. Coagulation studies initially showed prolonged prothrombin and partial thromboplastin times, but these returned to normal after treatment with oral vitamin $\mathrm{K}$ and were still normal one week later. On the forty fifth day, however, he had an intracranial haemorrhage due to vitamin $\mathrm{K}$ deficiency. The boy, who had been exclusively breast fed, had mild symptoms of liver disease and abnormal liver function test results due to $\alpha$-1-antitrypsin deficiency. Although oral vitamin $\mathrm{K}$ had not been given at birth, it seems unlikely that a smaller prophylactic dose given three weeks earlier would have been effective in preventing the intracranial haemorrhage.

Massive umbilical bleeding due to vitamin $\mathrm{K}$ deficiency was diagnosed in a 13 day old, breast fed girl. Hypoprothrombinaemia responded promptly to oral treatment with $2 \mathrm{mg}$ vitamin $\mathrm{K}_{1}$. Vitamin $\mathrm{K}$ deficiency, however, recurred four times despite treatment with oral vitamin $\mathrm{K}$ after each episode. Although no prophylactic oral vitamin $\mathrm{K}$ had been given before the initial bleeding, it seems unlikely that prophylaxis at birth would have been effective in preventing the bleeding as recurrent vitamin $\mathrm{K}$ deficiency after oral vitamin $\mathrm{K}$ prophylaxis could be due to malabsorption of the vitamin. ${ }^{12}$

Parenteral vitamin $\mathrm{K}$ was safe and provided the babies with a high dose of vitamin $\mathrm{K}^{3}$ : this might account for the fact that late onset vitamin $\mathrm{K}$ deficiency is rarely observed in babies given intramuscular prophylaxis, and it is certainly wiser to continue parenteral prophylaxis until the equivalent dose of oral vitamin $\mathrm{K}$ has been established to prevent late onset vitamin $\mathrm{K}$ deficiency.

The data presented in this paper encourage further studies to evaluate an appropriate dose regimen for oral vitamin $\mathrm{K}$ prophylaxis. Pharmacological studies ${ }^{3}$ and clinical experience, however, suggest that much higher or repeated oral doses are required to protect against late onset vitamin $\mathrm{K}$ deficiency.

This study was supported by Landesministerium für Wissenschaft und Forschung, North Rhine Westphalia.

\section{References}

' Garrow D, Chisholm M, Radford M. Vitamin K and Thrombotest values in full term infants. Arch Dis Child 1986;61: $349-51$.

2 O'Connor ME, Addiego JE. Use of oral vitamin $\mathrm{K}_{1}$ to prevent hemorrhagic disease of the newborn infant. J Pediatr 1986;108: 616-9.

${ }^{3}$ McNinch AM, Upton C, Samuels M, et al. Plasma concentrations after oral or intramuscular vitamin $\mathrm{K}_{1}$ in neonates. Arch Dis Child 1985;60:814-8.

4 Choonara IA, Park BK. Plasma concentrations after oral or intramuscular vitamin $\mathrm{K}_{1}$ in neonates. Arch Dis Child 1985;60: 1203-4.

5 von Kries R, Zenses C, Göbcl U. Immunoclectrophoretic determination of PIVKA II in capillary blood. Haemostasis 1985;15:42-3.

${ }^{6}$ Petrich C, Pothmann R, Döhmen A, von Voss H, Göbel U. A haematocrit corrected micro determination of the P \& P-test and blood clotting factors in capillary blood. Thrombosis et Diathesis Haemorrhagica 1974;32:510-9.

7 von Kries R, Göbel U, Maase B. Vitamin K deficiency in the newborn. Lancet 1985;ii:728-9.

${ }^{8}$ Wefring $\mathrm{KW}$. Hemorrhage in the newborn and vitamin $\mathrm{K}$ prophylaxis. J Pediatr 1962;61:686-71.

9 Motohara K. Endo F, Matsuda I. Effect of vitamin K administration on acarboxy-prothrombin (PIVKA II) levels in newborns. Lancet 1985;ii:242-4.

11 Shapiro AD, Hulac P, Jacobson LJ, Lane PA, Manco-Johnson MJ, Hathaway WM. Prevalence of vitamin $\mathrm{K}$ deficiency in newborn infants. Thromb Haemost 1985;54:125.

" von Kries R. Wahn V, Koletzko B, Göbel U. Späte Manifestation eines Vitamin $\mathrm{K}$ Mangels bei gestillten Säuglingen. Monatsschr Kinderheilkd 1984;132:292-5.

12 von Kries R, Reifenhäuser A, Göbel U, McCarthy P, Shearer MJ, Barkhan P. Late onset hacmorrhagic disease of newborn with temporary malabsorption of vitamin $\mathrm{K}_{1}$. Lancet 1985;i: 1035.

Correspondence to $\mathrm{Dr} \mathrm{R}$ von Kries, Universitätskinderklinik, Schlossmannhaus, Moorenstrasse 5, 4000 Düsseldorf 1, Federal Republic of Germany.

Received 14 April 1987 
IVU and DMSA scan and found the DMSA scan more sensitive for detecting established pyelonephritis in older children. ${ }^{4}$

It is now my practice to arrange a DMSA scan before a cystogram in all children over 1 year of age. There is no doubt that a DMSA scan is less traumatic to the child (and the radiologist) than a cystogram and should therefore be placed earlier in the diagnostic sequence. An abnormal DMSA scan is an absolute indication to proceed to a cystogram as more than two thirds of the children will have reflux. If the DMSA scan is normal reflux will be a rare event and probably of little long term significance, but a careful prospective study would be required to establish this point. In the meantime, I would urge paediatricians to request DMSA scans from their radiologist colleagues who will probably be delighted to carry out these relatively non- invasive tests particularly if such a change in policy results in fewer cystograms in the toddler age group.

References

1 White RHR. Management of urinary tract infection. Arch Dis Child 1987;62:421-7.

${ }^{2}$ Haycock GB. Investigation of urinary tract infection. Arch Dis Child 1986;61:1155-8.

${ }^{3}$ Meller ST. Focal bacterial nephritis in infancy: scintigraphic appearances. Nuc Med Commun 1982;3:111.

${ }^{4}$ Merrick MV, Uttley WS, Wild SR. The detection of pyelonephritic scarring in children by radioisotope imaging. $\mathrm{Br} J$ Radiol 1980;53:544-56.

S T MELLER

Queen Mary's Hospital for Children, Carshalton, Surrey SM5 4NR

\section{Corrections}

\section{When not to do a lumbar puncture}

In the annotation entitled 'When not to do a lumbar puncture' by DP Addy (Arch Dis Child 1987;62: 873-5) we apologise that the meaning of some sentences in the published version were not clear. The original version follows.

Page 874. Second sentence of second paragraph: Treatment including chloramphenicol will usually be adequate in meningitis caused by any of the usual three organisms. ${ }^{11}$

Page 874. Final sentence of left-hand column:

Whilst it may be wise to remove only a small amount of CSF when diagnostic lumbar puncture is performed, 'careful' lumbar puncture is not the answer since CSF leak through the punctured meninges may persist after the procedure.

Page 874. Third sentence of fourth paragraph: Fundal signs of raised pressure are not to be relied upon but evidence of incipient coning would make lumbar puncture a foolhardy procedure.

\section{Page 875. Penultimate paragraph:}

I shall consider treatment without lumbar puncture: when the diagnosis of meningitis seems clear and the child is very ill, or has a typical purpuric rash, or there is fundoscopic evidence of raised pressure, or there is impairment of consciousness, or there are other signs of incipient coning, or the child has been ill for several days.

\section{Acarboxyprothrombin activity after oral prophylactic vitamin $K$}

In the paper 'Acarboxyprothrombin activity after oral prophylactic vitamin K' by von Kries, Kreppel, Becker, Tangermann, and Göbel (Arch Dis Child 1987;62:938-40) we apologise that the word 'activity' should have been published as 'concentration' throughout the paper. 